\section{Unusual chromosomal variant in Klinefelter's syndrome}

Unusual variants of common conditions can be informative about the origins of abnormalities associated with those conditions. Classical cases of Klinefelter's syndrome have a combination of hypogonadism, azoospermia, small testes, tall stature, gynaecomastia, and diminished intelligence. This syndrome is usually associated with the karyotype $47 \mathrm{XXY}$. We therefore describe a patient with Klinefelter's syndrome in whom one of the $\mathrm{X}$ chromosomes is an isochromosome for the long arm, karyotype $47 \mathrm{XXqiY}$. The patient was of normal stature, had normal male habitus, and was of average intelligence. The patient's chromosome complement thus provided unique information about the influence on development of the individual arms of the $X$ chromosome.

\section{Case report}

A 36-year-old service engineer was referred to an endocrine clinic because of infertility after four years of marriage. Azoospermia had been documented on two occasions. The patient had been partially impotent for the previous six months. He had grown a beard while in the Merchant Navy and since leaving the Service had shaved daily. In the past he was said to have suffered from Reiter's syndrome.

His height was $164.5 \mathrm{~cm}$. He was of average intelligence, judged by his occupation and his response to investigative procedures. $\mathrm{He}$ had a normal male habitus, with normal male distribution of facial and body hair. There was no gynaecomastia. The testes were firm and small, volume $2 \mathrm{ml}$ each. We also obtained the heights of his family: father $165 \mathrm{~cm}$, mother $152 \mathrm{~cm}$, and sisters $162 \mathrm{~cm}$ and $150 \mathrm{~cm}$.

Investigations showed a low serum testosterone concentration of $5.9 \mathrm{nmol} / 1$ (laboratory normal range $8.5-27.5$ ), and raised gonadotropin concentrations: luteinising hormone $33.0 \mathrm{U} / 1$ (normal range $1-7)$, and follicle stimulating hormone $28.0 \mathrm{U} / 1$ (normal range 1-6). These findings indicated intrinsic gonadal failure. A skull $x$-ray film was normal. A culture of peripheral blood lymphocytes yielded cells of the karyotype $47 \mathrm{XXqiY}$, one of the $\mathrm{X}$ chromosomes being an isochromosome long arm (see figure). The mother and both sisters have normal karyotypes, $46 \mathrm{XX}$.

\section{Comment}

Chromosomally the patient differs from the normal male (46XY) in having an extra chromosome made up of two long arms of an $\mathrm{X}$ chromosome, (Xqi), and differs from the standard case of Klinefelter's syndrome $(47 \mathrm{XXY})$ in having no extra short arm (Xp) material and having two long arms of $\mathrm{X}(\mathrm{Xq})$ extra instead of the usual one $\mathrm{Xq}$ extra.

Evidently excess of $p$ arm material is not necessary to produce atrophy of the seminiferous tubules, sterility, and testosterone deficiency. Nevertheless, the complete androgenisation of facial and body hair is a small indication that excess of $p$ arm material contributes to the speed at which testicular atrophy occurs in people with an XXY configuration, although normal facial and body hair are occasionally seen in these patients. Klinefelter's syndrome is usually associated with diminished intelligence but many cases are seen with normal intelligence. In these respects our patient is therefore only a little unusual.

The stature of our patient is quite exceptional for Klinefelter's syndrome, being almost exactly that expected of a normal son of his parents, whereas persons with Klinefelter's syndrome are usually tall. We have compared his height with 42 cases, who were not inmates of mental deficiency hospitals and were aged between 18 and 60 years, reported by Court Brown et al. ${ }^{1}$ Their mean height was $178.4 \mathrm{~cm}$.
(SD 6.277) and our patient is shorter than all of them. On the other hand, six personal (JEG) cases of Klinefelter's syndrome with the karyotype $46 \mathrm{XX}$ had heights of $160,155,173,150,175$, and $170 \mathrm{~cm}$, and our patient fits neatly into their mean of $164 \mathrm{~cm}$.

The stature of our patient would support the idea that there are genes on the short arm of $\mathrm{X}(\mathrm{Xp})$, and on $\mathrm{Y}$, but not on the long arms of $X(X q)$, that act in a simple additive way to increase stature. Thus persons with $45 \mathrm{X}, 46 \mathrm{XXqi}$, and $46 \mathrm{XXp}^{-}$(deletion of short arm) configurations are all short; those with $46 \mathrm{XX}, 46 \mathrm{XXq}^{-}, 46 \mathrm{XY}$, and now $47 \mathrm{XXqiY}$, are normal in height for their sex; and $47 \mathrm{XXX}$, 47XXY, 47XYY are tall for their sex. The final stature in each case is also dependent on the rest of the genetical background and environment.

We have not found another published report of the karyotype 47XXqiY.

We thank Professor $\mathbf{R}$ Hall for his advice and encouragement.

${ }^{1}$ Court Brown, W M, et al, Medical Research Council Special Report Series No 305. London, HMSO, 1964.

(Accepted 20 fuly 1978)

Newcastle upon Tyne AHA(T)

ANNE GARDINER, BSC, cytogeneticist

Royal Victoria Infirmary, Newcastle upon Tyne

M M BROWN, BA, MB, senior house officer, endocrine unit (present address: National Hospital for Nervous Diseases, London WC1)

University of Newcastle upon Tyne

J E GRAY, MB, BS, former reader in anatomy

\section{Placement of central feeding catheters}

Long-term intravenous feeding in infants and children often requires the use of central veins. These may be approached percutaneously ${ }^{2}$ or by cutdown. The inferior vena cava, however, has been avoided owing to the risk of thrombosis and embolism. ${ }^{3}$ The advent of fine Silastic catheters has greatly diminished these risks. ${ }^{4}$

\section{Method and results}

Adequate sedation is essential for the procedure, which is carried out with full aseptic technique, preferably in the operating theatre. The distance from the groin to the sternum is measured. After skin preparation and infiltration with local anaesthetic an incision is made 1.5 to $2 \mathrm{~cm}$ below the medial end of the inguinal ligament. The long saphenous vein is then exposed by blunt dissection and transfixed with a fine needle. Cutting along the needle with a scalpel avoids inadvertent division of the vein (figure). A Silastic catheter $0.6 \mathrm{~mm}$ outside diameter (Dow Corning Corporation, Medical Products Division, Midland, Michigan) is then threaded in the required distance. It is unnecessary to ligate the lower end of the vein or to anchor the catheter within the vein. After further infiltration with local anaesthetic a 19G lumbar puncture needle is inserted in the anterior surface of the thigh 1 to $2 \mathrm{~cm}$ above the patella and advanced subcutaneously to the groin wound. The proximal end of the catheter is threaded through in retrograde fashion

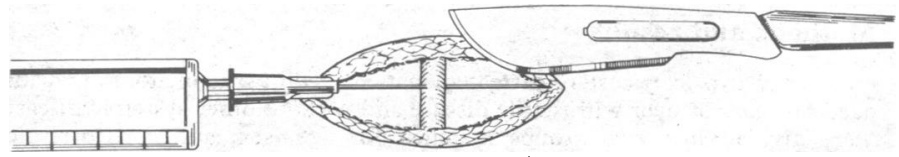

Opening the vein. 